\title{
Vitreous fluorophotometry in patients with cone-rod dystrophy
}

\author{
YOZO MIYAKE, SHU GOTO, ICHIRO OTA, AND HIROSHI ICHIKAWA \\ From the Department of Ophthalmology, Nagoya University, Nagoya, Japan
}

\begin{abstract}
SUMMARY 'Eight patients with cone-rod dystrophy were examined by means of vitreous fluorophotometry. The data in three patients with an early stage of retinitis pigmentosa (rod-cone dystrophy) served for comparison. In contrast with the abnormal findings on vitreous fluorophotometry in patients with an early stage of retinitis pigmentosa the value of vitreous fluorophotometry in cone-rod dystrophy was within the normal range in all patients except the two with advanced stages of this disease. Our results suggest that, although both diseases are based on diffuse dystrophy of photoreceptors, and the final stages of the two diseases may show several similar features, the process of breakdown of the blood retinal barrier differs greatly in the two diseases.
\end{abstract}

Cone-rod dystrophy is a syndrome characterised by progressive decrease of visual acuity, abnormal colour vision, and, in the electroretinogram, markedly decreased or absent cone components in the presence of reduced rod components. This syndrome has been described as cone dysfunction syndrome,' cone degeneration, ${ }^{2}$ progressive cone degeneration, ${ }^{3}$ cone dystrophy, ${ }^{4}$ progressive cone dystrophy, ${ }^{56}$ cone-rod degeneration, ${ }^{7}$ progressive cone-rod degeneration, ${ }^{\circ}$ cone-rod dystrophy," and progressive cone-rod dystrophy. ${ }^{1011}$ In its early stages cone components of the electroretinogram are more involved than rod components, " "which contrasts with retinitis pigmentosa as the representative of rod-cone dystrophy, wherein the rod system is affected first and the cone system later." 12 The visual functions and the fundus appearance of cone-rod dystrophies and rod-cone dystrophies may be similar in the advanced stages. ${ }^{70111.3}$ However, the impaired process of the retinal cells or retinal layers may be different in the two groups of dystrophies. Whereas many histological studies on retinitis pigmentosa have been reported, we found only one report of a patient with probable cone-rod dystrophy. ${ }^{13}$ That histological study was done when the disease was in an advanced stage, and the findings were similar to those in advanced stages of retinitis pigmentosa. The pathogenesis of cone-rod dystrophies, particularly in the early stage, remains obscure.

Correspondence to Yozo Miyake, MD.
Vitreous fluorophotometry is a sensitive and quantitative method for studying the blood-retinal barrier at two levels-the endothelial membrane of the retinal vessels (inner blood-retinal barrier) and the retinal pigment epithelium (outer blood-retinal barrier). ${ }^{1+15}$ Owing to the breakdown of the outer and inner blood-retinal barrier, patients with retinitis pigmentosa (rod-cone dystrophy) show a markedly abnormal value of vitreous fluorophotometry even in the early stage. ${ }^{1617}$ However, the function of the blood-retinal barrier in cone-rod dystrophy has not been studied.

We examined eight patients with various stages of cone-rod dystrophy using vitreous fluorophotometry. Results were compared with those obtained from three patients with retinitis pigmentosa in its early stage.

\section{Materials and methods}

After pupillary dilatation a $10 \%$ fluorescein sodium solution was injected into the antecubital vein at 10 $\mathrm{mg} / \mathrm{kg}$ of body weight, and fluorescein angiography was performed. One hour later a Goldmann contact lens was placed on the cornea and the vitreous fluorescein concentration was measured by slit-lamp fluorophotometry.

The apparatus and technique for fluorophotometry measurements have been described. ${ }^{1 \times 11}$ A Carl Zeiss (Jena) slit-lamp (Model 204) was modified by adding appropriate filters, a photometric detection system, 
and a device for electrical registration of the instrument's movement in the anterior-posterior axis. The posterior, middle, and anterior vitreous are sequentially brought into focus for fluorescein measurement by moving the joystick on the slit-lamp. The fibre optic probe is connected to a photomultiplier tube (Hamamatsu R 928), a sensitive amplifier, and an $X-Y$ recorder (Watanabe Sokki WX 441). The slit width was $0.7 \mathrm{~mm}$, and the angle between the exciting light and the viewing light was $10^{\circ}$.

In the present study the vitreous overlying the macula region was selected for recording. Only middle vitreous values, those measured in the area 5 $\mathrm{mm}$ anterior to the retinal surface, are considered here. With our vitreous fluorophotometry apparatus an upper limit of fluorescein dye concentration for the middle vitreous over the macula is $1 \cdot() \pm(0 \cdot 9 \times 10$ s $\mathrm{g} / \mathrm{ml}( \pm 2 \mathrm{SD})$, with the upper limit of $2 \cdot\left(0 \times 10^{\mathrm{s}} \mathrm{g} / \mathrm{ml}\right.$ in 30 normal subjects less than 50 years old.

Our methods for recording of electroretinogram and electro-oculogram have been described. ${ }^{20}$ After pupillary dilatation and 30 min of dark adaptation an electroretinogram was recorded with a Burian-Allen contact lens. A Ganzfeld stimulus was used to separate the rod and cone components of the electroretinogram. The scotopic electroretinogram was recorded with dim blue light in the dark, and the photopic electroretinogram was recorded with deep red light under blue background illumination. The blue light for the scotopic electroretinogram and the red light for the photopic electroretinogram are scotopically balanced. The photopic flicker electroretinogram are recorded with a $30 \mathrm{~Hz}$ stimulus of white light, and 16 responses were summated by a signal averager (Nihonkoden ATAC-250). The normal range $( \pm 2 \mathrm{SD})$ of amplitude in each component is $132 \pm 26 \mu \mathrm{V}$ (scotopic b), $45 \pm 15 \mu \mathrm{V}$ (pho- topic b), and $18 \pm 5 \mu \mathrm{V}$ (photopic flicker response). The electro-oculogram recordings were made in total darkness at $1 \mathrm{~min}$ intervals for $15 \mathrm{~min}$, followed by recordings under progressive light adaptation $(1000)$ lux) for $15 \mathrm{~min}$. The normal range of the ratio of light peak to dark trough (LP/DT ratio) in our laboratory is 1.71 to 2.94 .

\section{Results}

For the three patients with retinitis pigmentosa the hereditary pattern was autosomal dominant. Visual functions and the value of vitreous fluorophotometry are shown in Table 1. The patients were relatively young and their visual functions fairly well preserved. The vitreous lesions were minimal in cases 1 and 2 , and posterior vitreous detachment and liquefaction of the central vitreous were observed in case 3. The value of vitreous fluorophotometry was abnormal in all patients.

Table 2 shows age, sex, hereditary pattern, visual functions, and value of vitreous fluorophotometry for the eight patients with cone-rod dystrophy. In the electroretinogram all patients showed nearly absent cone components (photopic b, flicker) in the presence of reduced rod components (scotopic b). Two patients (cases 7 and 8) were in the far advanced stage of this disease. We have followed up these two patients for 10) to 15 years and found that the rod components initially present in the electroretinogram eventually disappeared. When the vitreous fluorophotometry was performed, not only the cone components but also the rod components were unrecordable in the electroretinogram. The value of vitreous fluorophotometry was within the normal range in six patients (cases 1, 2, 3, 4, 5, 6) and was abnormal in two patients (cases 7 and 8 ).

Table 1 Vitreous fluorophotometry, and visual functions in patients with retinitis pigmentosa

\begin{tabular}{|c|c|c|c|c|c|c|c|c|c|}
\hline \multirow{2}{*}{$\begin{array}{l}\text { Patient/age } \\
\text { (years/sex) }\end{array}$} & \multirow[t]{2}{*}{ Genetics } & \multirow[t]{2}{*}{ Eye } & \multirow{2}{*}{$\begin{array}{l}\text { Visual } \\
\text { acuity }\end{array}$} & \multicolumn{3}{|l|}{$E R G(\mu V)$} & \multirow{2}{*}{$\begin{array}{l}E O G \\
(L / D \text { ratio })\end{array}$} & \multirow{2}{*}{$\begin{array}{l}\text { Goldmann } \\
\text { visual field. } \\
\text { degrees }\end{array}$} & \multirow{2}{*}{$\begin{array}{l}\text { Vitreous fluoro- } \\
\text { photometry } \\
10^{-x} \mathrm{~g} / \mathrm{ml}\end{array}$} \\
\hline & & & & Photopic b & Flicker & Scotopic b & & & \\
\hline \multirow[t]{2}{*}{$1 / 13 / \mathrm{M}$} & \multirow[t]{2}{*}{$\overline{A D}$} & OD & $1 \cdot 0$ & 28 & 10 & NR & $1 \cdot 36$ & $\begin{array}{l}V-470 \\
V-125\end{array}$ & $5 \cdot()$ \\
\hline & & OS & 1.0 & 24 & 10 & NR & $1 \cdot 32$ & $\begin{array}{l}V-470 \\
V-125\end{array}$ & $4 \cdot 8$ \\
\hline \multirow[t]{2}{*}{ 2/34/M } & \multirow[t]{2}{*}{$A D$} & OD & $1 \cdot()$ & 14 & 8 & NR & $1 \cdot 28$ & $\begin{array}{l}V-472 \\
V-110\end{array}$ & $6 \cdot 2$ \\
\hline & & OS & $1 \cdot 2$ & 16 & 9 & NR & $1 \cdot 30$ & $\begin{array}{l}V-470 \\
V-120\end{array}$ & $5 \cdot 5$ \\
\hline \multirow[t]{2}{*}{$3 / 24 / F$} & \multirow[t]{2}{*}{ AD } & OD & $1 \cdot 2$ & 17 & $6 \cdot 5$ & NR & $1 \cdot 22$ & $\begin{array}{l}V-475 \\
V-120\end{array}$ & $7 \cdot 8$ \\
\hline & & OS & 0.9 & 10 & 7 & NR & $1 \cdot 34$ & $\begin{array}{l}V-465 \\
V-120\end{array}$ & $6 \cdot 4$ \\
\hline
\end{tabular}

AD indicates autosomal dominant: NR, nonrecordable; ERG; electroretinogram, EOG; clectro-oculogram. 
Fundus and fluorescein angiography revealed no pathological change in one patient (case 6). Seven patients-showed a bull's eye type of macular lesions with sharply defined zones of involved and uninvolved pigment epithelium. In addition to the bull's eye lesion some patients showed extensive and diffuse defects of pigment epithelium in the posterior pole (cases 1 and 3 ). In the two patients with advanced stages of the disease the fundus closely simulated the fundus of patients with retinitis pigmentosa associated with macular bull's eye lesion (cases 7 and 8).

Figs. 1-4 represent the spectrum of fluorescein angiographic changes seen in the eight patients. The pathological changes of the vitreous were unremarkable in cases $1,4,5$, and 6 . Partial detachment of the posterior vitreous was observed in cases 2 and 3. In cases 7 and 8 extensive liquefaction of the posterior and central vitreous was observed, as were some tobacco flecks in the gel and liquefied vitreous.

\section{Discussion}

As previously reported by others, we found that patients with retinitis pigmentosa (rod-cone dystrophy) in its early stage showed breakdown of the blood-retinal barrier measured by vitreous fluorophotometry. ${ }^{1617}$ The breakdown of the outer bloodretinal barrier (retinal pigment epithelium) is consistent with the histological findings of retinitis pigmentosa $a^{21}{ }^{23}$; that is, in retinitis pigmentosa the changes in the neuroepithelium and the pigmentary epithelium are directly related to each other.

However, in contrast to retinitis pigmentosa the value of vitreous fluorophotometry in cone-rod

Table 2 Vitreous fluorophotometry, and visual functions in patients with cone-rod dystrophy

\begin{tabular}{|c|c|c|c|c|c|c|c|c|c|}
\hline \multirow{2}{*}{$\begin{array}{l}\text { Patient/age } \\
\text { (years/sex) }\end{array}$} & \multirow[t]{2}{*}{ Genetics } & \multirow[t]{2}{*}{ Eye } & \multirow{2}{*}{$\begin{array}{l}\text { Visual } \\
\text { acuity }\end{array}$} & \multicolumn{3}{|l|}{$E R G(\mu V)$} & \multirow{2}{*}{$\begin{array}{l}E O G \\
(L / D \text { ratio })\end{array}$} & \multirow{2}{*}{$\begin{array}{l}\text { Goldmann } \\
\text { visual field. } \\
\text { degrees }\end{array}$} & \multirow{2}{*}{$\begin{array}{l}\text { Vitreous fluoro- } \\
\text { photometry } \\
10^{-*} \mathrm{~g} / \mathrm{ml}\end{array}$} \\
\hline & & & & Photopic $b$ & Flicker & Scotopic $b$ & & & \\
\hline \multirow[t]{2}{*}{$1 / 36 / \mathrm{M}$} & \multirow[t]{2}{*}{ SP } & OD & 0.4 & 12 & NR & 80 & 1.45 & $\begin{array}{l}V-465 \\
V-130\end{array}$ & 0.4 \\
\hline & & OS & 0.3 & 10 & NR & 76 & $1 \cdot 50$ & $\begin{array}{l}V-465 \\
V-130\end{array}$ & 0.5 \\
\hline \multirow[t]{2}{*}{$2 / 46 / M$} & \multirow[t]{2}{*}{$A R$} & OD & $0 \cdot 3$ & NR & NR & 50 & $1 \cdot 25$ & $\begin{array}{l}V-470 \\
V-160\end{array}$ & 0.7 \\
\hline & & OS & 0.3 & NR & NR & 55 & $1 \cdot 30$ & $\begin{array}{l}V-470 \\
V-160\end{array}$ & 0.8 \\
\hline \multirow[t]{2}{*}{$3 / 51 / F$} & \multirow[t]{2}{*}{$A R$} & OD & 0.1 & NR & NR & 45 & $1 \cdot 40$ & $\begin{array}{l}\text { V-4 70) } \\
\text { Ring scotoma }\end{array}$ & $0 \cdot 3$ \\
\hline & & OS & $0 \cdot 1$ & NR & NR & 50 & $1 \cdot 50$ & $\begin{array}{l}\text { V-4 70) } \\
\text { Ring scotoma }\end{array}$ & $0 \cdot 3$ \\
\hline \multirow[t]{2}{*}{$4 / 34 / M$} & \multirow[t]{2}{*}{$\mathrm{SP}$} & OD & 0.1 & NR & NR & 50 & 1.42 & $\begin{array}{l}V-465 \\
V-155\end{array}$ & 0.4 \\
\hline & & OS & 0.1 & NR & NR & 52 & $1 \cdot 40$ & $\begin{array}{l}V-465 \\
V-155\end{array}$ & 0.4 \\
\hline \multirow[t]{2}{*}{$5 / 19 / \mathrm{M}$} & \multirow[t]{2}{*}{$\mathrm{AR}$} & OD & $0 .(1) 8$ & NR & NR & 42 & $1 \cdot 75$ & $\begin{array}{l}V-465 \\
V-150\end{array}$ & 0.7 \\
\hline & & OS & $(0 \cdot() 7$ & NR & NR & 40 & $1 \cdot 80$ & $\begin{array}{l}V-465 \\
V-150\end{array}$ & $0 \cdot 6$ \\
\hline \multirow[t]{2}{*}{ 6/37/M } & \multirow[t]{2}{*}{ SP } & OD & 0.1 & NR & NR & 40 & Uncxamined & $\begin{array}{l}V-470 \\
V-160\end{array}$ & 0.5 \\
\hline & & OS & $0 \cdot 3$ & NR & NR & 43 & Uncxamined & $\begin{array}{l}V-470 \\
V-160\end{array}$ & $0 \cdot 4$ \\
\hline \multirow[t]{2}{*}{$7 / 40 / \mathrm{M}$} & \multirow[t]{2}{*}{ SP } & OD & 0.4 & NR & NR & NR & Unexamined & $\begin{array}{l}\text { V-4 40 } \\
\text { Ring scotoma }\end{array}$ & $3 \cdot 6$ \\
\hline & & OS & 0.5 & NR & NR & NR & Uncxamined & $\begin{array}{l}\text { V-4 40 } \\
\text { Ring scotoma }\end{array}$ & $3 \cdot 8$ \\
\hline \multirow[t]{2}{*}{$8 / 25 / F$} & \multirow[t]{2}{*}{ SP } & OD & $(0 \cdot 2$ & NR & NR & $N R$ & $1 \cdot 00$ & $\begin{array}{l}\text { V-4 } 65 \\
\text { Ring scotoma }\end{array}$ & $4 \cdot 4$ \\
\hline & & OS & $0 \cdot 2$ & NR & NR & NR & 1.05 & $\begin{array}{l}\mathrm{V} \cdot 465 \\
\text { Ring scotoma }\end{array}$ & $3 \cdot 8$ \\
\hline
\end{tabular}

AR indicates autosomal recessive; SP, sporadic: NR, nonrecordable, ERG: electroretinogram, EOG; electro-oculogram. 


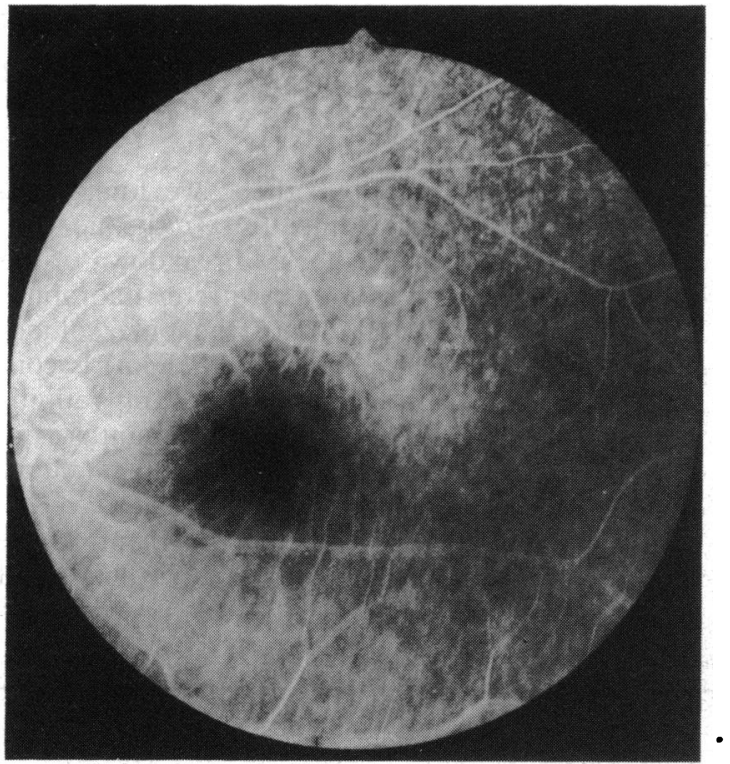

Fig. 1 Left fundus in case 6. Fluorescein angiogram in late arteriovenous phase. No abnormality was found.

dystrophy was within the normal range in all patients except the two with advanced stages of the disease. Because of the paucity of histological study the basic defect in cone-rod dystrophy remains obscure. However, the difference in fluorophotometry findings suggests a different underlying pathogenetic mechanism between these two disorders, particularly in the early stages. Unlike retinitis pigmentosa, the extensive involvement of the retinal pigment epithelium may occur only in the late stage of cone-rod dystrophy. However, it remains to be refuted that the

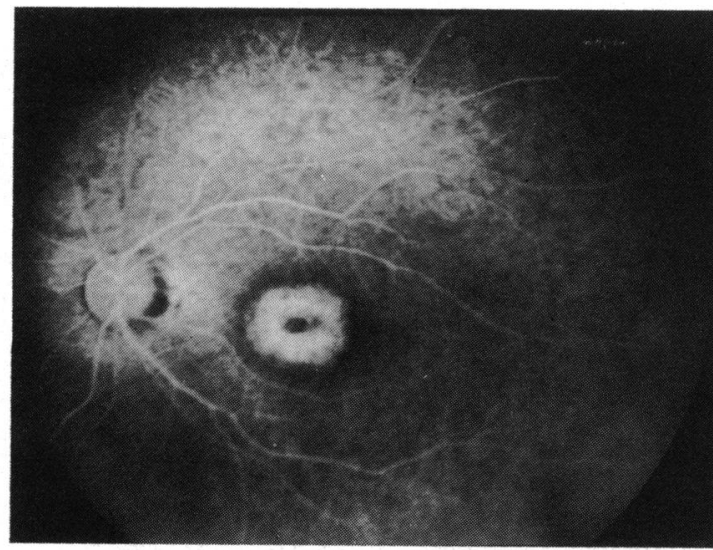

Fig. 2 Left fundus in case 5. Fluorescein angiogram in late arteriovenous phase. A bull's eye configuration of hyperfuorescence was noted.

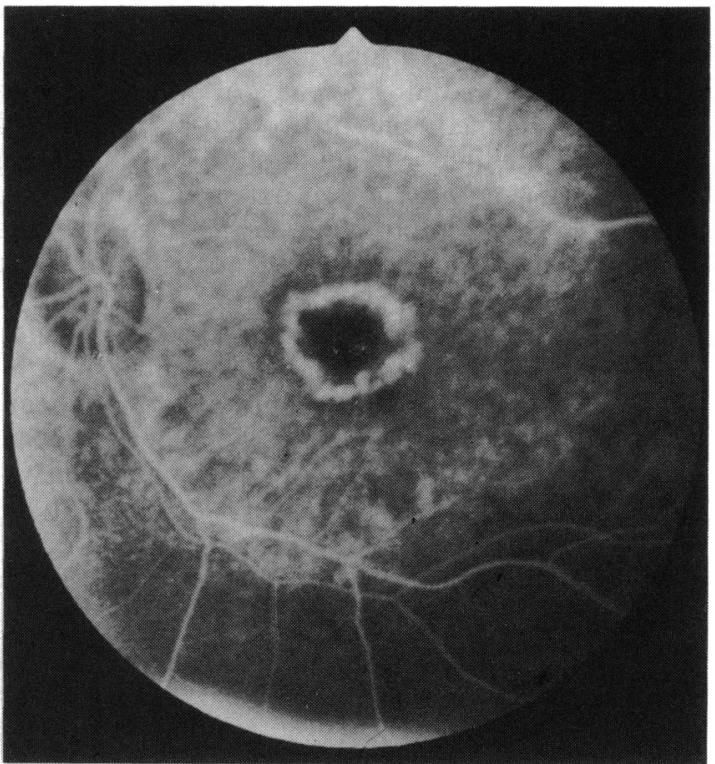

Fig. 3 Left fundus in case 3. Fluorescein angiogram in arteriovenous phase. In addition to a bull's eye region extensive and diffuse defect of pigment epithelium was noted in the posterior pole.

retinal pigment epithelium is not defective early in the course of the disease in patients with cone-rod dystrophy, but in a manner that does not compromise the blood-retinal barrier. In most of our patients with

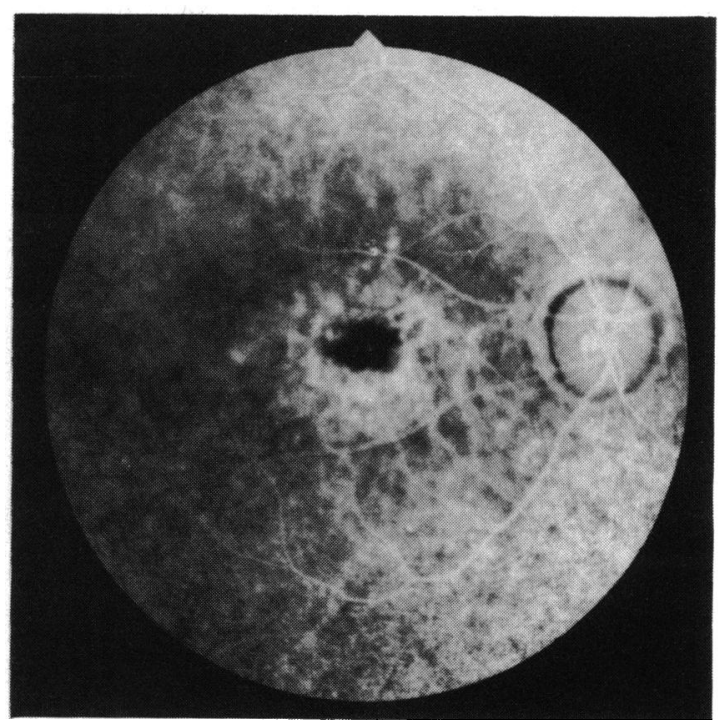

Fig. 4 Right fundus in case 8. Fluorescein angiogram in late arteriovenous phase. In addition to a bull's eye region the pigment epithelium defect was noted all over the fundus. The retinal arterioles were attenuated. 
cone-rod dystrophy fluorescein angiography revealed a ring-shaped window defect in the macula and/or some diffuse hyperfluorescence in the posterior pole. The normal values of vitreous fluorophotometry in these patients suggest that intercellular retinal pigment epithelial barriers, as well as intercellular and membrane transport systems also responsible for the outer blood-retinal barrier, can remain functional, as reported in fundus flavimaculatus. ${ }^{24}$

Although both cone-rod dystrophy and retinitis pigmentosa (rod-cone dystrophy) are diffuse photoreceptor diseases, and the final stage of these two different diseases may show several similar aspects, our results suggest that the process of breakdown of the blood-retinal barrier differs greatly in the two diseases.

\section{References}

1 Goodmann G. Ripps H, Sicgel M. Conc dysfunction syndromes. Arch Ophthalmol 1963; 70: 214-31.

2 Krill AE. The electroretinographic and electrooculographic findings in patients with macular lesions. Trans Am Acad Ophthalmol Otolaryngol 1966: 70: 106.3-83.

3 Berson EL, Gouras P, Gunkel RD. Progressive cone degeneration, dominantly inherited. Arch Ophthalmol 1968; 80: 77-83.

4 Krill AE, Deutman AF. Dominant macular degenerations: the conc dystrophies. A m J Ophthalmol 1972; 73: 352-69.

5 Ohba N. Progressive conc dystrophy; four cases of unusual form. JpnJ Ophthalmol 1974; 18: 5()-69.

6 François J, De Rouck A. DeLacy JJ. Progressive conc dystrophics. Ophthalmologica 1976; 173: 81-101.

7 Heckenlively JR, Martin DA. Rosales TO. Telangiectasia and optic atrophy in conc-rod degencrations. Arch Ophthalınol 1981: 99: $|983-9|$.

8 Berson EL. Gouras P, Gunkel RD. Progressive cone-rod degencration. Arch Ophthalmol 1968; 80: 68-75.

9 Krill AE. Cone degenerations. In: Krill AE, ed. Hereditary retinal and choroidal diseases. Hagerstown. Harper and Row. 1977: 421-78.
10) Fishman GA. Progressive human conc-rod dysfunction (dystrophy). Trans Am Acad Ophthalmol Otolaryngol 1976; 81: 716-24.

11 Miyakc Y. Ichikawa K. Tokuda H. Ichikawa H. The clinical properties in progressive cone-rod dystrophy. Jpn (lin Ophthalmol 1982: 36: 323-9.

12 Gouras P, Carr RE. Electrophysiological studics in carly retinitis pigmentosa. Arch Ophthalmol 1964; 72: 104-10.

13 Vail D. Shoch D. Hereditary degeneration of the macula. II. Follow-up report and histopathologic study. Trans $A m(O p /$ thalmol Soc 1965: 63: 51-69.

14 Cunha-Vaz JG, Abreu JRF. Campos AJ, et al. Early breakdown of the blood-retinal barrier in diabetes. Br J Ophthalmol 1975; 59: $649-56$.

15 Cunha-Vaz JG. The blood-ocular barriers. Surv Ophthalmol 1979; 23: 279-96.

16 Fishman GA. Cunha-Vaz JG. Salzano T. Vitreous fluorophotometry in patients with retinitis pigmentosa. Arch Ophthalmol 1981: 99: 12(1)-7.

17 Prager TC, Chu H, Garcia CA. Anderson RE. The influence of vitreous change on vitreous fluorophotometry. Arch Ophthalmol 1982: 100: 594-6.

18 Ichikawa H. Ando F. Yasuma T. Goto S. Studies on disturbances in the blood-retinal barrier. 1. A trial to measure the fluorescein concentration in the vitreous. Nippon Ganka Gakkai Zasshi (Tokyo) 1980); 84: 736-44.

19 Miyake Y, Goto S. Ando F, Ichikawa H. Vitreous fluorophotometry in congenital stationary nightblindness. Arch Ophthalmol 1983; 101: 574-6.

20 Miyake Y, Harada K. Familial fleck retina with nightblindness. Ann Ophthalmol 1982: 14: 836-41.

21 Mizuno K. Hoshino M. Miyake Y. Ultrastructural study of the retina in retinitis pigmentosa. Jpn (lin Ophthalmol 1983; 37: 315-9.

22 Kolb H. Gouras P. Electron microscopic observations of human retinitis pigmentosa, dominantly inherited. Invest Ophthalmol Visual Sci 1974: 13: 487-98.

23 Szamier RB, Berson EL. Klein R. Meyers S. Sex-linked retinitis pigmentosa: ultrastructure of photoreceptors and pigment epithelium. Invest Ophuhalmol Visual Sci 1979; 18: 145-60).

24 Fishman GA, Cunha-Vaz JG. Travassos AC. Vitreous fluorophotometry in pationts with fundus flavimaculatus. Arch $O p / h$ thalmol 1982; 100: $11186-8$ 